\title{
Targeted next-generation sequencing panels in the diagnosis of Charcot-Marie-Tooth disease
}

Andrea Cortese, MD, PhD, Janel E. Wilcox, MS, CGC, James M. Polke, PhD, Roy Poh, PhD, Mariola Skorupinska, MA, Alexander M. Rossor, FRCP, PhD, Matilde Laura, MD, Pedro J. Tomaselli, MD, Henry Houlden, MD, PhD, Michael E. Shy, MD, and Mary M. Reilly, MD, FRCPI, FRCP

Neurology ${ }^{\circledR}$ 2020;94:e51-e61. doi:10.1212/WNL.0000000000008672

\section{Abstract}

\section{Objective}

To investigate the effectiveness of targeted next-generation sequencing (NGS) panels in achieving a molecular diagnosis in Charcot-Marie-Tooth disease (CMT) and related disorders in a clinical setting.

\section{Methods}

We prospectively enrolled 220 patients from 2 tertiary referral centers, one in London, United Kingdom $(\mathrm{n}=120)$, and one in Iowa $(\mathrm{n}=100)$, in whom a targeted CMT NGS panel had been requested as a diagnostic test. PMP22 duplication/deletion was previously excluded in demyelinating cases. We reviewed the genetic and clinical data upon completion of the diagnostic process.

\section{Results}

After targeted NGS sequencing, a definite molecular diagnosis, defined as a pathogenic or likely pathogenic variant, was reached in $30 \%$ of cases $(n=67)$. The diagnostic rate was similar in London (32\%) and Iowa (29\%). Variants of unknown significance were found in an additional $33 \%$ of cases. Mutations in GJB1, MFN2, and MPZ accounted for 39\% of cases that received genetic confirmation, while the remainder of positive cases had mutations in diverse genes, including SH3TC2, GDAP1, IGHMBP2, LRSAM1, FDG4, and GARS, and another 12 less common genes. Copy number changes in PMP22, MPZ, MFN2, SH3TC2, and FDG4 were also accurately detected. A definite genetic diagnosis was more likely in cases with an early onset, a positive family history of neuropathy or consanguinity, and a demyelinating neuropathy.

\section{Conclusions}

NGS panels are effective tools in the diagnosis of CMT, leading to genetic confirmation in onethird of cases negative for PMP22 duplication/deletion, thus highlighting how rarer and previously undiagnosed subtypes represent a relevant part of the genetic landscape of CMT.

\author{
Correspondence \\ Dr. Reilly \\ m.reilly@ucl.ac.uk
}

\section{MORE ONLINE}

\section{ค Podcast}

Dr. Michelle Mauermann talks with Dr. Mary Reilly about her paper on targeted next-generation sequencing panels in the diagnosis of Charcot-Marie-Tooth disease.

NPub.org/wkykkn 


\section{Glossary}

CMT $=$ Charcot-Marie-Tooth disease CMTES $=$ CMT examination score; CMTNS $=$ Charcot-Marie-Tooth neuropathy score; $\mathbf{d H M N}=$ distal hereditary motor neuropathy; HSN = hereditary sensory neuropathy; MLPA = multiplex ligationdependent probe amplification; NGS = next-generation sequencing; NHNN = National Hospital for Neurology and Neurosurgery; VUS = variants of unknown significance; WES $=$ whole exome sequencing.

Charcot-Marie-Tooth disease (CMT) and related disorders distal hereditary motor neuropathy (dHMN) and hereditary sensory neuropathy (HSN) represent the most common heritable neurologic conditions and to simplify discussion all 3 diseases are referred to as CMT in this article. ${ }^{1}$ To date, over 90 genes have been associated with CMT and the number is increasing. ${ }^{2}$

Despite the genetic heterogeneity underlying CMT, to date up to $90 \%$ of all genetically confirmed cases across different cohorts are reportedly due to mutations in only 4 genesPMP22 duplication/deletion and mutations in PMP22, GJB1, $M F N 2$, and MPZ-while up to $40 \%$ of patients remain genetically undiagnosed. ${ }^{3-5}$ This is not surprising if one considers that, until recently, molecular diagnosis of CMT has relied on multiplex ligation-dependent probe amplification (MLPA) for chr17p12 and conventional Sanger sequencing of these major causative genes.

In recent years, genetic diagnosis of inherited diseases has evolved rapidly with the advent of next-generation sequencing (NGS). NGS technology allows multiple parallel sequencing of the whole human genome (whole genome sequencing), its protein coding sequences (whole exome sequencing [WES]), or specific genes of interest (targeted multigene panels).

Application of WES to molecularly undefined families with CMT has enabled the recent exponential growth in discovery of genes associated with CMT. WES has also proved effective in the screening of patients with CMT for known genes, achieving a molecular diagnosis in $9 \%-45 \%$ of cases, depending on the characteristics of the cohort and the criteria used for classifying causative mutations. ${ }^{6-9}$ This notwithstanding, implementation of WES in the diagnostic practice is hampered by its suboptimal gene coverage, as well as the large volume of data generated.

In recent years, customized targeted NGS panels of diseaserelevant genes have been the preferred method for employing NGS in clinical practice and offer a high degree of coverage of the selected genes.

Several groups have published their use of custom NGS panels in the diagnosis of CMT in a research setting and validated its efficacy in detecting point mutations, small insertions, and deletions as well as larger rearrangements, including the common chr17p12 duplication causing CMT1A. ${ }^{10-16}$ Nevertheless, there are limited data on the effect of targeted NGS panels on the genetic diagnosis of CMT in everyday clinical practice. ${ }^{17-20}$ This study describes the effect of targeted NGS panels on the molecular diagnosis of CMT and related disorders in routine clinical practice in 2 specialized clinics in different health systems in the United Kingdom (London) and United States (Iowa).

\section{Methods}

\section{NGS panels}

In London, NGS was performed by the National Hospital for Neurology and Neurosurgery's (NHNN) United Kingdom Accreditation Service-accredited genetic diagnostic laboratory where 50 genes associated with CMT and related conditions were sequenced (uclh.nhs.uk/OurServices/ServiceA-Z/Neuro/ NEURG/NGLAB/Pages/UCLHNeurogeneticspanels.aspx). Subgroups of the panel can also be ordered for phenotypedriven targeted sequencing (e.g., HSN) varying from 11 to 50 genes. In the NHNN laboratory, enrichment was performed with an Illumina (San Diego, CA) custom Nextera Rapid Capture panel prior to NGS on an Illumina MiSeq, Hiseq 2500, or NextSeq 500. All coding exons of the RefSeq transcripts of the genes and 15 base pairs of the flanking introns were targeted, except for GJB1, for which the target region is extended 860 bases upstream of the ATG start codon to include the nervespecific promoter region, and NTRK1, for which the targeting is extended to include the known splicing mutation c.851-33T $>$ A. Variants that are pathogenic, likely to be pathogenic, and of uncertain clinical significance were confirmed by bidirectional Sanger sequencing. Over $99 \%$ of the coding exons of all genes in the panel were sequenced to a read depth of $30 \times$ or greater in almost all cases.

In Iowa, NGS study was outsourced to accredited commercial companies, which returned detailed information on $51 \pm 23$ (18-135) sequenced and analyzed genes.

A full list of genes sequenced and analyzed in London and Iowa is provided in table e-1 (doi.org/10.5061/dryad.kp8pb51). Mutations were classified according to the 2015 American College of Medical Genetics Standards and Guidelines for the interpretation of sequence variants ${ }^{21}$ and cases with pathogenic or likely pathogenic mutations were considered as genetically confirmed. All cases were discussed after NGS testing in a multidisciplinary setting including CMT specialist neurologists, geneticists, genetic counselors, neurophysiologists, and neuropathologists, where appropriate. 


\section{Data collection and statistical analyses}

Patients with CMT attending specialized inherited neuropathy clinics in both centers were enrolled from January 2015 to December 2017. Patients were diagnosed with CMT based on the presence of a slowly progressive neuropathy with or without family history and after exclusion of other common causes of acquired neuropathy. After review of clinical charts, the following information was recorded for all patients: age at NGS testing (enrollment), age at onset, sex, family history of neuropathy or consanguinity, symptoms at onset, additional phenotype, and motor conduction velocity of nondominant median or ulnar nerve during first nerve conduction study available. CMT subtype was classified as CMT if both motor and sensory nerves were similarly affected, and dHMN or HSN if the neuropathy showed exclusive or predominant involvement of motor or sensory nerves, respectively. CMT cases were further subdivided into demyelinating CMT if conduction velocity of the nondominant median or ulnar nerve was $\leq 38 \mathrm{~m} / \mathrm{s}$ and axonal or intermediate CMT if $>38$ $\mathrm{m} / \mathrm{s}$. Disease severity was scored using the previously validated Charcot-Marie-Tooth neuropathy score (CMTNS, v2) or CMT examination score (CMTES, v2) ${ }^{22}$ and cases were divided into mild (CMTNS 0 to 10 or CMTES 0 to 7 ), moderate (CMTNS 11 to 20 or CMTES 8 to 16), and severe (CMTNS 21 to 36 or CMTES 17 to 28). In cases for which CMTNS or CMTES had not been collected, disease was considered mild if walking was possible without aid, moderate if walking was possible with foot orthosis or ankle dorsiflexion was $<3$ Medical Research Council grade, and severe if patients needed a walking aid, such as a stick or a wheelchair. Continuous data are shown as mean \pm SD. Differences between groups were determined with 2-tailed $t$ test for quantitative variables, with $\chi^{2}$ test for categorical variables, as appropriate. A multivariate logistic regression was performed to assess the association of relevant clinical variables with a positive result of targeted NGS testing. Pearson correlation coefficient was calculated to test association of presence or number of variants of unknown significance (VUS) and disease severity. All analyses were performed using STATA statistical software, version 14 .

\section{Standard protocol approvals, registrations, and patient consents}

The study was approved by local institutional ethical committees. Written informed consent was obtained from all patients (or guardians of patients) participating in the study.

\section{Data availability}

Anonymized data from this study will be shared by request from any qualified investigator.

\section{Results}

\section{Patient cohorts}

A total of 220 consecutive patients with CMT were enrolled from January 2015 to December 2017 in London $(n=120)$ or
Iowa $(\mathrm{n}=100)$. Relevant demographic and clinical features are summarized in table 1 . Sixty-one percent were male and mean age at enrollment was $49 \pm 17$ years. The most frequent CMT subtype in enrolled cases was axonal or intermediate CMT ( $\mathrm{n}=143,65 \%)$, followed by demyelinating CMT $(\mathrm{n}=$ $41,19 \%)$, dHMN ( $n=21,9 \%)$, and HSN $(n=15,7 \%)$. The proportion of patients with dHMN and HSN was higher in London than Iowa, where the majority of cases had axonal or intermediate CMT; however, there was no significant difference in the proportion of patients with demyelinating CMT. PMP22 duplication/deletion was excluded in all patients with typical demyelinating CMT prior to NGS testing. Twenty patients had an independent risk factor for neuropathy including diabetes $(n=9)$, paraprotein $(n=4)$, previous chemotherapy $(n=2)$, rheumatoid arthritis $(n=2)$, Sjögren syndrome $(n=1)$, high alcohol consumption $(n=1)$, or renal transplant $(n=1)$. In 16 of the 220 cases, a diagnosis of CMT was considered the most likely diagnosis justifying genetic testing but was not definite. This reflects real-life clinical practice. In Iowa, there was a higher percentage of familial cases, but the number of cases with onset of the neuropathy before 20 years of age was lower compared to the London cohort. Patients in London more frequently had undergone previous genetic testing by Sanger sequencing of candidate genes compared to patients in Iowa, likely due to insurance coverage restrictions in the United States.

\section{Genetic diagnosis}

After targeted NGS sequencing, a genetic diagnosis, defined as a pathogenic or likely pathogenic variant, was reached in $30 \%$ of cases $(n=67)$ (tables 2 and e-2 [doi.org/10.5061/ dryad.kp8pb51]). The diagnostic rate was similar in London (32\%) and Iowa (29\%). The proportion of cases with a genetic diagnosis was higher for demyelinating CMT $(n=30 /$ $41,73 \%)$ compared to axonal or intermediate CMT $(n=32 /$ $143,22 \%), \operatorname{dHMN}(n=3 / 21,14 \%)$, or HSN $(n=2 / 15,13 \%)$ (figure 1). Overall, variants in GJB1 $(\mathrm{n}=12)$, SH3TC2 $(\mathrm{n}=8), \operatorname{MFN2}(\mathrm{n}=8)$, and MPZ $(\mathrm{n}=6)$ accounted for half of the genetically confirmed patients, followed by GDAP1 $(\mathrm{n}=4)$, IGHMBP2 $(\mathrm{n}=4)$, LRSAM1, FDG4 and GARS $(\mathrm{n}=3$ per gene), AARS, LITAF, and PMP22 ( $\mathrm{n}=2$ per gene). Nine patients had mutations in an additional 9 different genes.

In Iowa, mutations in GJB1, MPZ, and MFN2 accounted for $66 \%$ of genetically confirmed cases $(n=19)$, followed by SH3TC2 (3 cases) and 5 less common genes.

In London, only $18 \%$ of solved cases had a mutation in GJB1, $M P Z$, or MFN2 $(\mathrm{n}=7)$. Five patients had mutations in SH3TC2. Mutations in LRSAM1, FDG4, GDAP1, AARS, and $I G H M B P 2$ collectively accounted for a third of genetically confirmed patients.

Copy number variants were identified in 7 patients (3\%) and in 5 of them were considered pathogenic or likely pathogenic including whole gene deletion of PMP22, whole gene duplication of MPZ, exonic deletions of MFN2 (exons 7 and 8), 
Table 1 Demographic and clinical features of the Charcot-Marie-Tooth (CMT) patient cohort undergoing targeted nextgeneration sequencing (NGS)

\begin{tabular}{|c|c|c|c|c|}
\hline & All $(n=220)$ & London $(n=120)$ & lowa $(n=100)$ & $p$ Value \\
\hline Male, n (\%) & $136(61)$ & $79(66)$ & $57(57)$ & NS \\
\hline Age, y (current), mean \pm SD & $49 \pm 17$ & $47 \pm 19$ & $50 \pm 17$ & NS \\
\hline Age at onset below $20 \mathrm{y}, \mathrm{n}(\%)$ & 109 (49.5) & $68(57)$ & $41(41)$ & 0.02 \\
\hline Family history of neuropathy or consanguinity, $\mathrm{n}(\%)$ & $109(50)$ & $40(48)$ & $61(61)$ & 0.002 \\
\hline Ethnicity, n (\%) & & & & NS \\
\hline Caucasian & $202(92)$ & $105(88)$ & $97(97)$ & \\
\hline South Asian & $9(4)$ & $9(7)$ & $0(0)$ & \\
\hline Middle Eastern & $5(2)$ & $4(3)$ & $1(1)$ & \\
\hline Hispanic & $2(1)$ & $1(1)$ & $1(1)$ & \\
\hline Other & $2(1)$ & $1(1)$ & $1(1)$ & \\
\hline CMT subtype, n (\%) & & & & $<0.001$ \\
\hline Demyelinating CMT & $41(19)$ & $26(22)$ & $15(15)$ & \\
\hline Axonal CMT & $143(65)$ & $65(53)$ & $79(79)$ & \\
\hline dHMN & $21(9)$ & $18(15)$ & $3(3)$ & \\
\hline HSN & $15(7)$ & $12(10)$ & $3(3)$ & \\
\hline Possible CMT, n (\%) & $16(7)$ & $13(11)$ & $3(3)$ & 0.03 \\
\hline Previous Sanger sequencing of CMT genes, $\mathbf{n}(\%)$ & $83(38)$ & $74(61)$ & $9(9)$ & $<0.001$ \\
\hline No. of genes tested by NGS panel, mean \pm SD (range) & $36 \pm 22(11-135)$ & $24 \pm 10(11-54)$ & $51 \pm 23(18-135)$ & $<0.001$ \\
\hline
\end{tabular}

Abbreviations: $\mathrm{dHMN}=$ distal hereditary motor neuropathy; $\mathrm{HSN}=$ hereditary sensory neuropathy; NS = not significant.

SH3TC2 (exon 7), and a 90-base pair deletion in exon 5 of FDG4.

Overall, 30 pathogenic or likely pathogenic mutations were novel.

\section{Predictors of positive targeted NGS testing}

Patients who received a genetic diagnosis after targeted NGS sequencing were more likely to have an earlier age at onset, a positive family history, or a demyelinating neuropathy. These variables were confirmed to be independent predictive factors of positive NGS testing in a multivariate logistic regression model (table 3 ). In only 1 out of 16 patients with a low pretest probability of having CMT did NGS testing yield a positive result. Sex, number of genes present on NGS panels, and disease severity were not associated with achievement of a genetic diagnosis.

\section{Ancillary testing}

In order to confirm or reject a variant found by NGS as causative of the neuropathy, additional investigations were performed in 57 cases (26\%), including 25 cases $(21 \%)$ in London and 32 cases in Iowa (32\%). Segregation analysis was the most common ancillary investigation performed
(51 cases). Long-range PCR followed by Sanger sequencing or MLPA were performed in 5 cases to confirm large rearrangements, including whole gene deletion of PMP22 and whole gene duplication of $M P Z$, exonic deletion of MFN2 (exons 7 and 8), SH3TC2 (exon 7) (figure 2A), and a 90-base pair deletion in exon 5 of FDG4 (figure 2B). RNA studies were performed in order to determine the effect of a novel homozygous 892-1 G>T variant in NDRG1 on splicing. cDNA from RNA for peripheral blood showed that the splicing mutation leads to a 9-base pair deletion (c.892 900delCCGGCCAAG) resulting in an in-frame deletion of $\overline{3}$ amino acids (figure 2C). In vitro studies were performed to gather additional functional evidence of pathogenicity of a noncoding mutation in the $3^{\prime} \mathrm{UTR}$ of $G J B 1^{23}$ and to test the loss-of-function effect of a novel variant in AARS in a yeast aminoacylation complementation assay. Plasma concentrations of 1-deoxy-sphinganine and 1-deoxymethyl-sphinganine are currently being measured in 3 cases with variants in SPTLC1 and SPTLC2.

\section{Variants of unknown significance}

Ninety-eight VUS were found in 73 patients, including 52 cases for which no other pathogenic or likely pathogenic variant could be identified (table 4). Heterozygous variants in 
Table 2 Genetic distribution in molecularly confirmed cases

\begin{tabular}{|c|c|c|c|c|c|c|c|c|c|}
\hline \multirow[b]{2}{*}{ Gene } & \multicolumn{3}{|c|}{ Both centers } & \multicolumn{3}{|l|}{ London } & \multicolumn{3}{|l|}{ lowa } \\
\hline & $N=220$ & $\begin{array}{l}\% \text { Of all } \\
\text { cases }\end{array}$ & $\begin{array}{l}\% \text { Of genetically } \\
\text { confirmed }\end{array}$ & $N=120$ & $\begin{array}{l}\% \text { Of all } \\
\text { cases }\end{array}$ & $\begin{array}{l}\% \text { Of genetically } \\
\text { confirmed }\end{array}$ & $N=100$ & $\begin{array}{l}\% \text { of all } \\
\text { cases }\end{array}$ & $\begin{array}{l}\% \text { of genetically } \\
\text { confirmed }\end{array}$ \\
\hline GJB1 & 12 & 5.5 & 17.9 & 4 & 3.3 & 10.5 & 8 & 8 & 27.6 \\
\hline SHзTC2 & 8 & 3.6 & 11.9 & 5 & 4.2 & 13.2 & 3 & 3 & 10.3 \\
\hline MFN2 & 8 & 3.6 & 11.9 & 1 & 0.8 & 2.6 & 7 & 7 & 24.1 \\
\hline$M P Z$ & 6 & 2.7 & 8.9 & 2 & 1.7 & 5.3 & 4 & 4 & 13.8 \\
\hline GDAP1 & 4 & 1.8 & 5.9 & 3 & 2.5 & 7.9 & 1 & 1 & 3.4 \\
\hline IGHMBP2 & 4 & 1.8 & 5.9 & 2 & 1.7 & 5.0 & 2 & 2 & 6.9 \\
\hline LRSAM1 & 3 & 1.4 & 4.5 & 3 & 2.5 & 7.9 & - & & - \\
\hline FDG4 & 3 & 1.4 & 4.5 & 3 & 2.5 & 7.9 & - & & - \\
\hline GARS & 3 & 1.4 & 4.5 & 1 & 0.8 & 2.6 & 2 & 2 & 6.9 \\
\hline AARS & 2 & 0.9 & 3 & 2 & 1.7 & 5.3 & - & & - \\
\hline LITAF & 2 & 0.9 & 3 & 1 & 0.8 & 2.6 & 1 & 1 & 3.4 \\
\hline PMP22 & 2 & 0.9 & 3 & 1 & 0.8 & 2.6 & 1 & 1 & 3.4 \\
\hline HSPB8 & 1 & 0.5 & 1.5 & 1 & 0.8 & 2.6 & - & & - \\
\hline KIF5A & 1 & 0.5 & 1.5 & 1 & 0.8 & 2.6 & - & & - \\
\hline MTMR2 & 1 & 0.5 & 1.5 & 1 & 0.8 & 2.6 & - & & - \\
\hline$S B F 2^{a}$ & 1 & 0.5 & 1.5 & 1 & 0.8 & 2.6 & - & & - \\
\hline NDRG1 & 1 & 0.5 & 1.5 & 1 & 0.8 & 2.6 & - & & - \\
\hline NEFL & 1 & 0.5 & 1.5 & 1 & 0.8 & 2.6 & - & & - \\
\hline SCN9A & 1 & 0.5 & 1.5 & 1 & 0.8 & 2.6 & - & & - \\
\hline SPTLC2 & 1 & 0.5 & 1.5 & 1 & 0.8 & 2.6 & - & & - \\
\hline TRPV4 & 1 & 0.5 & 1.5 & 1 & 0.8 & 2.6 & - & & - \\
\hline Total & 67 & 30.5 & 100 & 38 & 31.7 & 100 & 29 & 29 & 100 \\
\hline
\end{tabular}

a Formerly MTMR13.

SH3TC2, NTRK1, PRX, NGF, and PLEKHG5 and other genes associated with autosomal recessive CMT accounted for half of cases. VUS were also found frequently in AARS, DYNC1H1, and SPTLC1 and their interpretation was often challenging. Eighteen cases had more than one VUS. A detailed list is provided in table e-3 (doi.org/10.5061/dryad. $\mathrm{kp} 8 \mathrm{pb} 51$ ). Multiple reasons prevented the interpretation of a VUS as causative of the neuropathy, including the presence of the variant in public healthy control databases (20 cases, $27 \%$ ), novel variants (17 cases, $23 \%$ ), weak in silico predicted scores of pathogenicity (10 cases, $15 \%$ ), poor conservation of the mutated amino acid across species (7 cases, 9\%), and a lack of functional evidence of pathogenicity ( 8 cases, $11 \%$ ). Evaluation of the clinical phenotype was used to exclude a VUS as pathogenic in 27 patients (36\%).

There was no significant difference in the presence of VUS identified in patients with $(31 \%, \mathrm{n}=21)$ or without $(34 \%$, $\mathrm{n}=52$ ) a definite molecular diagnosis (Pearson $\chi^{2}=0.15, p$ value $=0.7$ ), number of VUS in patients with ( 1 VUS in $27 \%$, $\mathrm{n}=18 ; 2$ VUS in $3 \%, \mathrm{n}=2 ; 3$ or more VUS in $3 \%, \mathrm{n}=2$ ) or without ( 1 VUS in $25 \%, \mathrm{n}=39$; 2 VUS in $7 \%, \mathrm{n}=10 ; 3$ or more VUS in $3 \%, \mathrm{n}=4$ ) a definite molecular diagnosis (Poisson $\chi^{2}=-0.16, p$-value $\left.=0.76\right)$, nor was there a correlation between the presence (Pearson correlation coefficient $=-0.06, p$ value $=0.6$ ) or number (Pearson correlation coefficient $=-0.16, p$ value $=0.2$ ) of additional VUS and disease severity in genetically confirmed patients.

\section{Clinical features of the most common genetic CMT subgroups}

Mutations in GJB1, including 3 mutations in noncoding regions of the gene, 2 in the promoter, and 1 in the $3^{\prime}$ UTR, were found in 6 male and 6 female participants, thus representing the most common genetic subgroup identified (17\% of solved cases). The clinical features were similar to those 

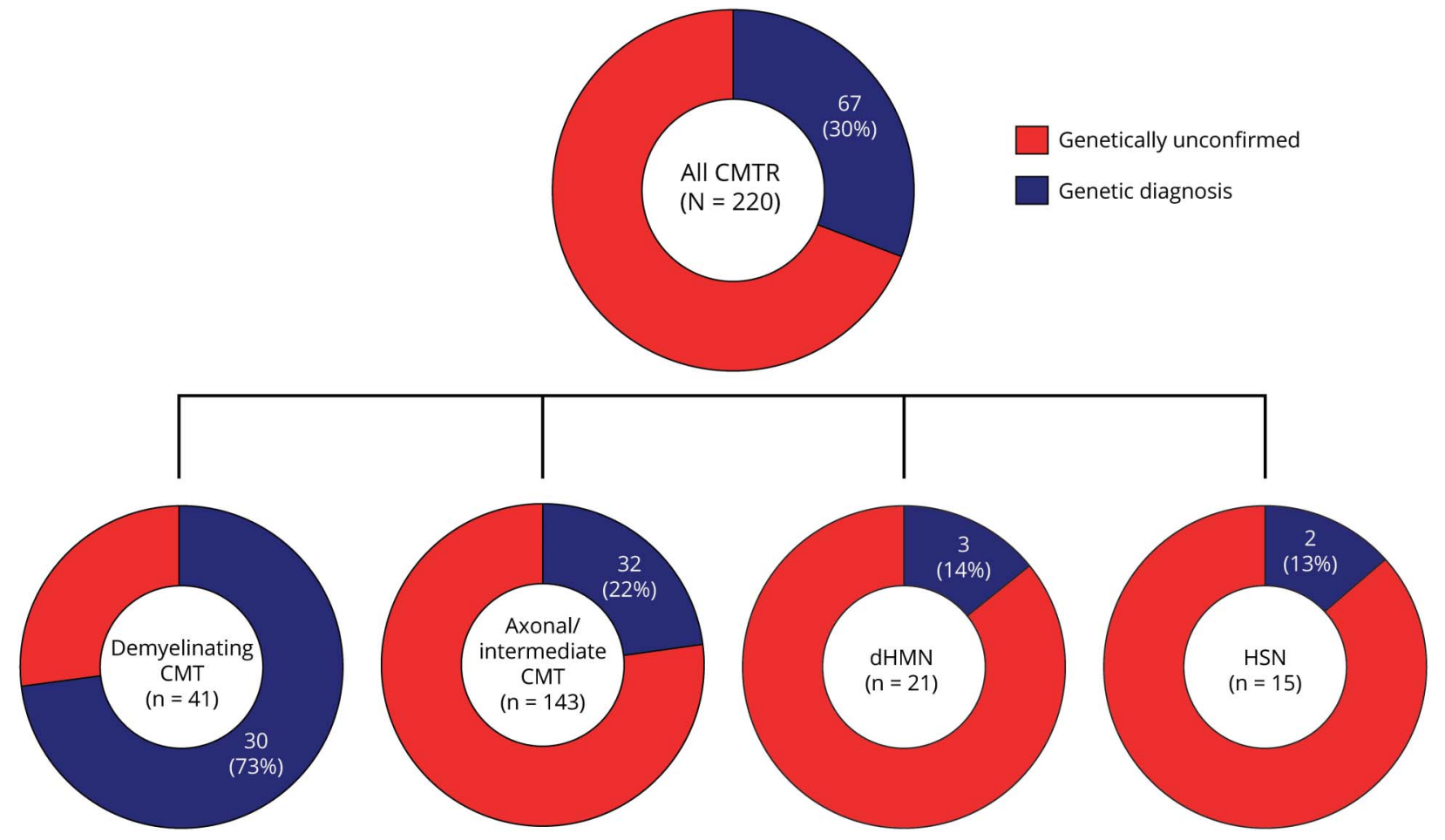

CMTR = Charcot-Marie-Tooth disease and related disorders; $\mathrm{dHMN}$ = distal hereditary motor neuropathy; HSN = hereditary sensory neuropathy.

described previously. ${ }^{24,25}$ Male participants had onset in the first or second decade, disease severity was more frequently moderate, and conduction velocity in the intermediate to demyelinating range. Female participants had onset in the second or third decade. In female participants, conduction velocities were normal in 2 cases, reduced in the intermediate range in 3, and slow in the CMT1 range in 1. Disease severity was variable.

With 8 cases diagnosed, recessive mutations in SH3TC2 accounted for $12 \%$ of solved CMT cases and $27 \%$ of the demyelinating CMT subtype. Patients were all of Caucasian origin, symptom onset was usually reported in the first decade, and motor milestones were frequently delayed. Scoliosis was observed in 6 cases and cranial nerve involvement was reported in 3. However, progression of the neuropathy was generally slow, and its severity moderate. Conduction velocities were reduced, ranging from 20 to $33 \mathrm{~m} / \mathrm{s}$. An illustrative case of the utility of unbiased parallel sequencing followed by segregation analysis vs candidate-gene direct sequencing in interpreting single variants is highlighted by the case of 2 affected brothers with CMT1 who were previously given a diagnosis of CMT1C due to a novel c.115C $>\mathrm{T}$ p.(Pro39Ser) mutation in LITAF identified by Sanger sequencing. The affected patients had early scoliosis and deafness, which is unusual in LITAF-related CMT1C. After the mutation was detected in an unaffected sister, further family analysis was performed with NGS, which revealed 2 compound heterozygous pathogenic mutations in SH3TC2 (c.2860C > T p.[Arg954Ter] and c.3303delG p.[Arg1101SerfsTer15]), which segregated with the disease in the family and led to reclassification of the c.115C $>\mathrm{T}$ p.(Pro39Ser) in LITAF as a VUS.

Mutations in MFN2, including one case with 2 recessive variants, a c.449G $>\mathrm{T}$ p.(Gly150Val) missense variant in compound heterozygous state with a deletion of exons $7-8$, and one previously reported case ${ }^{26}$ with 2 semidominant c.749G $>$ A p. (Arg250Gln) and c.1085C $>$ G p.(Thr362Arg) missense mutations, accounted for $12 \%$ of all CMT cases and $37 \%$ of axonal CMT cases who received genetic confirmation. Onset was variable, ranging from 3 to 52 years, and the severity ranged from mild to severe, with higher disability observed in a case carrying 2 semidominant mutations.

Six patients had mutations in $M P Z$, including 4 missense mutations, 1 mutation affecting a splicing site, and 1 wholegene duplication. Three cases had onset in the first 2 years of life with delayed walking and slow or unrecordable nerve conduction velocities. Three additional cases had adult onset including 2 with axonal neuropathy of moderate severity.

Four patients had mutations in GDAP1. Two patients with recessive mutations in GDAP1 presented with an early onset, severe neuropathy associated with vocal cord paralysis. Motor action potentials were not recordable. Two patients carrying 
Table 3 Variables associated with positive targeted next-generation sequencing panel testing

\begin{tabular}{|c|c|c|c|c|}
\hline & $\begin{array}{l}\text { Pathogenic or likely pathogenic mutation detected } \\
\text { (genetically confirmed) }(n=67), n(\%)\end{array}$ & $\begin{array}{l}\text { No pathogenic mutation } \\
\text { detected }(n=153), n(\%)\end{array}$ & $\begin{array}{l}p \\
\text { Value }^{a}\end{array}$ & $\begin{array}{l}\text { OR }(95 \% \\
\text { CI), }{ }^{b} p \text { Value }\end{array}$ \\
\hline Early onset (1st-2nd decade) & $54(81)$ & $56(37)$ & 0.00 & $\begin{array}{l}5.2 \\
(2.4-11.0) \\
0.00\end{array}$ \\
\hline $\begin{array}{l}\text { Positive family history or } \\
\text { consanguinity }\end{array}$ & $46(68)$ & $63(41)$ & 0.00 & $\begin{array}{l}3.8(1.8-7.9), \\
0.00\end{array}$ \\
\hline Conduction velocity $<38 \mathrm{~m} / \mathrm{s}$ & $28(42)$ & $13(8)$ & 0.00 & $\begin{array}{l}6.1 \\
(2.5-14.8), \\
0.00\end{array}$ \\
\hline $\begin{array}{l}\text { Possible CMT (other cause possibly } \\
\text { explaining the neuropathy) }\end{array}$ & $1(1)$ & $15(10)$ & 0.03 & NS \\
\hline
\end{tabular}

Abbreviations: $\mathrm{CMT}=$ Charcot-Marie-Tooth disease; $\mathrm{Cl}$ = confidence interval; NS = not significant; OR = odds ratio.

Variables significantly associated with genetic confirmation in a univariate $\chi^{2}$ test $\left({ }^{a}\right)$ were tested in a multivariate logistic regression model $\left({ }^{b}\right)$.

single missense mutations had a milder axonal neuropathy with later onset. Pyramidal signs were present in one case.

Four patients were found to have homozygous or compound heterozygous variants in IGHMBP2 causing severe autosomal recessive axonal CMT with early onset. Two unrelated cases carrying the same c.1325A $>$ G p.(Tyr442Cys) homozygous variant and both from the Middle East had associated respiratory failure and recurrent gastric distention. In one patient, which has been previously reported, this was associated with hyperhidrosis of the hands and feet. ${ }^{27}$

Probable pathogenic mutations in LRSAM1 were identified in 3 CMT2 cases from London. All mutations were inside or in close proximity to the RING finger domain, where all previous pathogenic dominant mutations have been reported. Of note, 2 had prominent vibratory sense loss in the lower limbs.

Three patients with mutations in FDG4 presented with earlyonset moderate to severe autosomal recessive CMT1 associated with scoliosis and cranial nerve involvement and very slow conduction velocities in the region of $10 \mathrm{~m} / \mathrm{s}$.

Five cases with dominant axonal CMT or dHMN had mutations in tRNA-synthetase genes: 3 in GARS and 2 in $A A R S$. Two patients with GARS mutations presented with the characteristic hand weakness and atrophy.

\section{Discussion}

This study provides evidence that targeted NGS panels are a useful tool for the molecular diagnosis of CMT in a clinical setting and are able to diagnose a third of patients not carrying the $17 \mathrm{p}$ duplication.

Previous studies have shown that NGS panels are technically robust in terms of coverage and read depth and have reported rates of molecular diagnosis in inherited neuropathies ranging from $6 \%$ to $46 \%{ }^{10-19}$ The differences in the diagnostic rate in these studies both between each other and compared to ours may be explained by the differences in the specific features of the cohorts being tested coming from general neurology, genetic or specialized inherited neuropathy clinics, the number of demyelinating CMT cases enrolled, and the variable exclusion of more common causative genes by previous MLPA and Sanger sequencing. As opposed to demyelinating cases, over $70 \%$ of axonal CMT cases remain genetically unconfirmed after NGS panel testing. NGS panels only explore a very limited part of the coding genomic DNA. Recent studies have shown that a significant part of the missing heritability in neurologic diseases as well as hereditary neuropathies may be hidden in noncoding regions of the human genome. ${ }^{28-31}$ The increased identification of mutations in noncoding DNA regions will likely lead to a reduction of the percentage of patients without a molecular diagnosis.

Of interest, $3 \%$ of patients who underwent NGS panel testing had copy number variants in one of the CMT-causing genes. Previous reports also demonstrated the ability of NGS to identify duplications and deletions in chromosome $17 \mathrm{p} 12$, as well as copy number variants in other genes. ${ }^{14,17}$ Besides the common PMP22 rearrangements, pathogenic copy number variants are known in MPZ, GJB1, MFN2 (in compound heterozygous state with a second pathogenic mutation), NDRG1, GAN, and SEPT9. ${ }^{32,33}$ More recently, a $78-\mathrm{kb}$ duplication of chromosome 8q24.3 locus at chromosome $\mathrm{Xq} 27.1$ and a $1.35-\mathrm{Mb}$ duplication of chromosome $7 \mathrm{q} 36.3$ were identified as the cause of CMTX3 and $d H M N 1$, respectively. ${ }^{32}$ Our study identified novel pathogenic copy number variants in FDG4 and SH3TC2 and suggest that implementation of NGS panels in a diagnostic setting will lead to an increased identification of structural variants in known CMT genes.

In contrast to most previous studies, we aimed at evaluating the accuracy of NGS panels in a real-life clinical specialist setting. We prospectively enrolled 220 patients accessing specialist clinics for CMT in the United Kingdom and United 
A.a

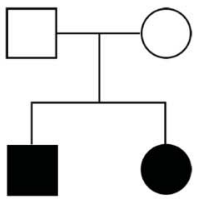

II-1 (case 122)
A.b

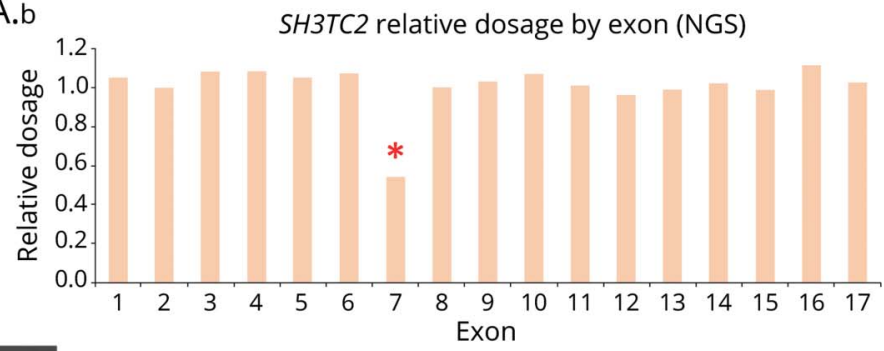

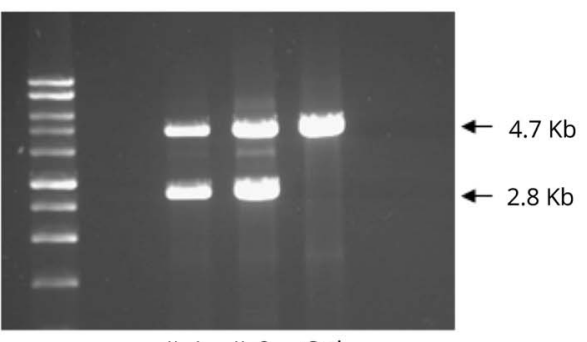

$\begin{array}{lll}\|-1 & \text { II-2 } & \mathrm{Ctrl}\end{array}$
SH3TC2 relative dosage by exon (NGS)

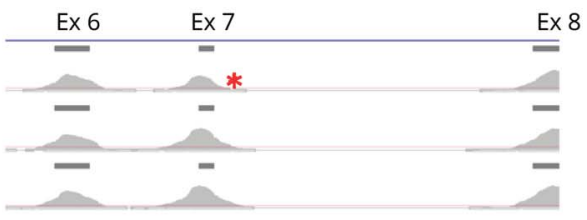

B

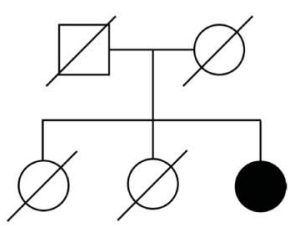

Case 177

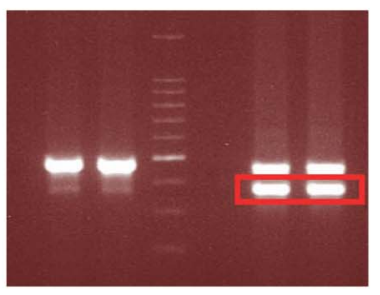

Ctrl1 Ctrl2

Case 177

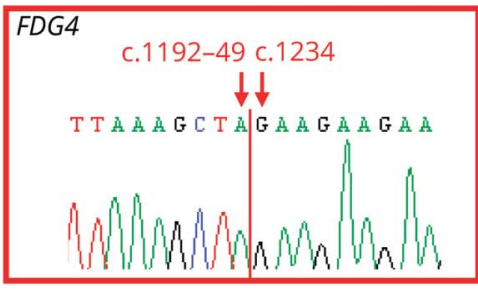
(duplicated)

C

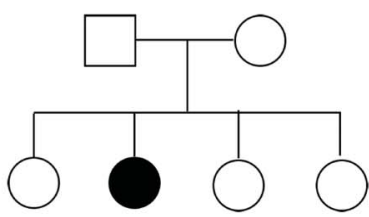

Case 164

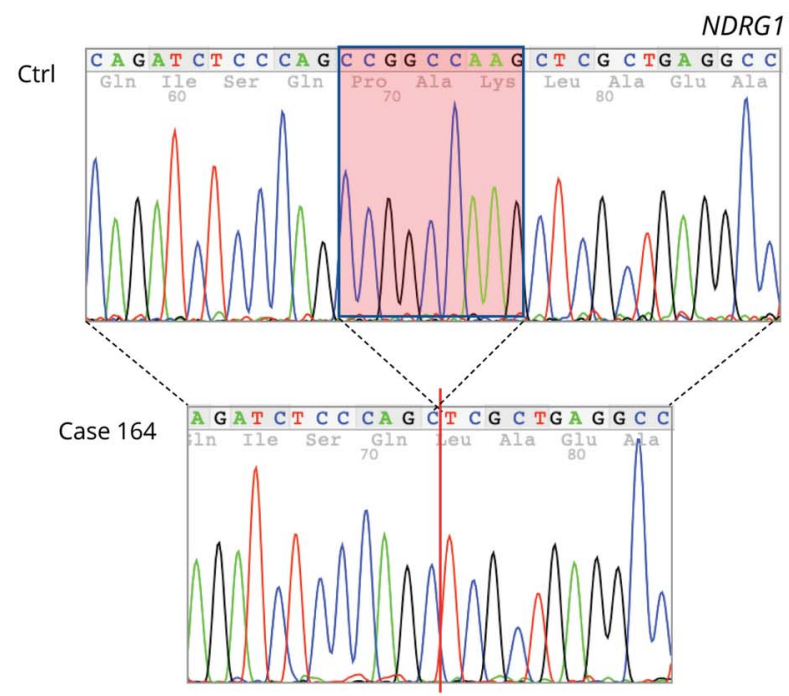

(A) Case 122 presented with early onset of demyelinating neuropathy associated with scoliosis and cranial nerve involvement. He had a sister with a similar condition. NGS for genes associated with Charcot-Marie-Tooth disease type 1 (CMT1) and intermediate was performed and identified a single C.386-2A>C mutation in SH3TC2. Relative read-depth analysis of NGS was performed (A.b) looking for copy number variant in SH3TC2 and identified a deletion of exon 7 (indicated by a red * on the read depth plots), which was confirmed by long PCR in both siblings (A.a), in compound heterozygous state with the c.386-2A>C. (B) Patient 139 was diagnosed in the first decade of life with CMT1. A targeted NGS panel was performed at age 72 , which identified 2 variants in FDG4 1304 1305delinsAA p.(Arg435GIn) and FDG4:c.1192-48_1233del. Long-range PCR was performed followed by Sanger sequencing of the gel band-extracted PCR product (red square box) identifying the breakpoints of 90-base pair FGD4 deletion. (C) Patient 164 presented with early-onset CMT1. NGS targeted panel for CMT1 genes was performed at age 35 and identified a homozygous 892-1 G>T variant in NDRG1, bearing potential to disrupt splicing of the flanking exons. RNA was extracted from peripheral blood and retrotranscribed into cDNA showing that the splicing mutation leads to a 9-base pair deletion of NDRG1 transcript (c.892_900delCCGGCCAAG) resulting in an in-frame deletion of 3 amino acids (red box). As opposed to typical CMT4D cases due to stop mutations in NDRG1, patient 164 presented a relatively mild neuropathy without clinical evidence of hearing loss, suggesting that the splicing mutation leading to in-frame deletion of 3 amino acidic residues may not abolish NDRG1 function. 
Table 4 Genes with identified variants of unknown significance

\begin{tabular}{ll}
\hline Gene name & $\mathrm{N}$ \\
\hline SH3TC2 & 10 \\
\hline AARS & 7 \\
\hline DYNC1H1 & 5 \\
\hline IGHMBP2 & 4 \\
\hline NTRK1 & 4 \\
\hline PRX & 4 \\
\hline PLEKHG5 & 3 \\
\hline SCN9A & 3 \\
\hline SPTLC1 & 3 \\
\hline DCTN1 & 3 \\
\hline DNMT1 & 2 \\
\hline DST & 2 \\
\hline EGR2 & 2 \\
\hline IKBKAP & 2 \\
\hline LMNA & 2 \\
\hline NDRG1 & 2 \\
\hline NGF & 2 \\
\hline SLC52A2 & 2 \\
\hline Other VUS & 2 \\
\hline Total & 2 \\
\hline INK1 & 2 \\
\hline
\end{tabular}

States and for whom NGS panels had been requested as a diagnostic test. We reviewed their genetic and clinical data upon completion of the diagnostic process in a multidisciplinary setting as this is a crucial step in modern genetic diagnostic practice.

This study confirms that mutations in GJB1, MFN2, and $M P Z$ account for a significant proportion (39\%) of genetically confirmed cases of CMT as we and others had shown in previous studies using sequential Sanger testing. ${ }^{4,5}$ The remaining $61 \%$ of genetically diagnosed cases encompass mutations in various less common genes. It is interesting to note that mutations in these genes accounted for only $6 \%-10 \%$ of genetically confirmed cases in our 2 previous studies, which looked at the prevalence of CMT genetic subtypes in the London and Iowa (previously Detroit) cohorts based on traditional Sanger sequencing. ${ }^{4,5}$ Although a direct comparison is not possible, as some of the genes here identified were not known at that time, this would correspond to an increase of the diagnostic yield for these rarer genetic subtypes by 6 - to 10 -fold, thus highlighting the effectiveness of unbiased NGS panel testing in the diagnosis of
CMT. As per our inclusion criteria, those percentages do not completely reflect the distribution of subtypes and mutations in the CMT population, since PMP22 duplication and deletions were excluded prior to enrollment in typical demyelinating cases, leading to a reduced inclusion of these patients compared to those with axonal/intermediate CMT subtypes.

Of note, in Iowa, mutations in one of the 3 common genes (GJB1, MFN2, MPZ) explained over $65 \%$ of positive cases vs only $18 \%$ in London. The discrepancy is likely due to differences in the baseline features of patients enrolled. In London, a significant number of patients had previously been tested for mutations in these genes by Sanger sequencing as this is available freely throughout the United Kingdom in the National Health Service in neurology and genetic clinics and, if present, NGS testing was not requested. This may have led to a selection bias in the London cohort towards the enrollment of rarer genetic subtypes, while the frequency of mutations identified in Iowa may reflect more reliably their actual prevalence in the general CMT population. Differences in the ethnicities of patients enrolled in the 2 centers may have also skewed the mutational spectrum towards rarer subtypes in the London population.

In both cohorts, and in keeping with previous reports, ${ }^{34-36}$ SH3TC2 appears to be a common cause of autosomal recessive CMT in the Caucasian population, explaining over one-fourth of all demyelinating cases after exclusion of the PMP22 duplication/deletion, and followed by FDG4. Recessive mutations in GDAP1 and IGHMBP2 were also frequently identified in early-onset and severe axonal CMT cases. Three novel mutations and one novel VUS in LRSAM1 were identified in the London cohort in patients with moderately severe axonal neuropathy and prominent sensory loss. Mutations in tRNA synthetase genes, GARS and AARS, were also well-represented among the identified genetic subtypes. A VUS in MARS was identified in one case whose neuropathy was otherwise explained by a likely pathogenic mutation in LRSAM1, while no cases with mutations in HARS, YARS, or $K A R S$ were identified.

A positive family history for neuropathy in dominant or $\mathrm{X}$-linked cases and consanguineous marriages in recessive cases, an early age at onset of the neuropathy, and the presence of reduced conduction velocities were found to be independent predictors of positive testing by NGS panels. In fact, only 4/55 (7\%) sporadic axonal or intermediate CMT cases with onset after 20 years received genetic confirmation in the present study compared to 17/18 (94\%) early-onset familial demyelinating CMT cases tested. The percentage of genetically confirmed cases dropped to $5 \%$ in patients with atypical features or for whom a nongenetic cause of the neuropathy could not be ruled out. This is in keeping with previous studies showing that the age at onset is a strong predicting factor for obtaining a genetic diagnosis. ${ }^{11}$ 
The average price of an NGS panel covering 20 genes in the United Kingdom is $£ 800$ ( $\sim \$ 1,000$ USD), corresponding to an average cost of $£ 40$ per gene. Considering that the traditional Sanger sequencing price ranges from $£ 200$ to $£ 500$, so over 10-fold higher, NGS panels appear to be effective both from a diagnostic as well as from an economic point of view.

While NGS sequencing is able to sequence multiple genes in a fraction of the time compared to sequential Sanger sequencing, the time and expertise required for the analysis of the many variants identified has greatly increased. In particular, the interpretation of VUS remains one of the largest diagnostic challenges in the NGS era. Misclassification of a VUS as causative or benign may have major clinical and legal implications, especially if one thinks of the available family planning options (e.g., prenatal or preimplantation diagnosis) that patients may undertake after receiving a molecular diagnosis. In our study, VUS were identified in approximately one-third of tested cases. Single variants in genes associated with CMT in a recessive state were by far the most common type of VUS. Although their interpretation as not causative by themselves of the neuropathy may seem relatively straightforward, they require careful consideration as large rearrangements or variants in promoter/noncoding regions on the other allele could be missed by both NGS and Sanger sequencing, as exemplified by 2 cases here reported carrying point mutations in SH3TC2 or FDG4 in one allele and a larger rearrangement on the other allele. Introducing whole genome analysis into clinical practice will greatly assist the analysis of these cases.

Of interest, a previous study had identified that the number of rare VUS in neuropathy-associated genes, including single mutations in autosomal recessive CMT genes, was significantly higher in patients with CMT vs unaffected controls. ${ }^{9}$ These variants were shown to interact genetically in a zebrafish model, exacerbating their phenotype. The authors concluded that the combinatorial effect of rare variants could contribute to the disease burden in CMT and partly explain its variable phenotypic expressivity. Taking advantage of the large dataset collected in this study, we analyzed our data to see whether the presence of additional VUS could aggravate the phenotype in genetically confirmed patients. We did not observe any significant differences in disease severity in solved cases carrying additional VUS vs those without a second variant. The genetic heterogeneity of the cohort examined and the relatively low number of patients per single genes could be a major limiting factor in the interpretation of the negative finding, as a VUS could act as a modifier for a particular CMT subtype but not others.

Finally, we have confirmed that NGS can accurately detect copy number changes at the whole gene as well as single exon level, both for $P M P 22$ as well as in other genes including MPZ, MFN2, SH3TC2, and FDG4. To our knowledge, copy number variations in SH3TC2 and FDG4 were not previously reported as causative of CMT. This finding highlights how structural variants in known CMT genes could potentially account for part of the current missing heritability in CMT.

Our study has shown that, after exclusion of the common PMP22 duplication/deletion, NGS panels can achieve a molecular diagnosis in one third of CMT cases tested in a specialized clinical diagnostic setting, which includes a dedicated post genetic analysis multidisciplinary case discussion. Sixty percent of the genetically confirmed cases carried variants in heterogeneous and often very rare genes, whose identification would have been extremely laborious by direct sequencing of candidate genes. Early disease onset, a positive family history or consanguinity, and reduced nerve conduction velocities were predictive of achieving a positive genetic diagnosis.

\section{Author contributions}

Andrea Cortese: drafting/revising the manuscript, data acquisition, study concept or design, analysis or interpretation of data, accepts responsibility for conduct of research and final approval, acquisition of data, statistical analysis. Janel Wilcox: drafting/revising the manuscript, data acquisition, study concept or design, accepts responsibility for conduct of research and final approval, acquisition of data. James M. Polke: drafting/revising the manuscript, data acquisition, study concept or design, analysis or interpretation of data, accepts responsibility for conduct of research and final approval, acquisition of data, study supervision. Roy Poh: drafting/ revising the manuscript, analysis or interpretation of data, accepts responsibility for conduct of research and final approval, acquisition of data. Mariola Skorupinska: data acquisition, accepts responsibility for conduct of research and final approval, acquisition of data, study supervision. Alexander Rossor: drafting/revising the manuscript, accepts responsibility for conduct of research and final approval, acquisition of data. Matilde Laura: drafting/revising the manuscript, accepts responsibility for conduct of research and final approval. Pedro J. Tomaselli: data acquisition, analysis or interpretation of data, accepts responsibility for conduct of research and final approval, acquisition of data. Henry Houlden: drafting/revising the manuscript, study concept or design, analysis or interpretation of data, accepts responsibility for conduct of research and final approval, contribution of vital reagents/tools/patients, acquisition of data, study supervision. Michael E. Shy: drafting/revising the manuscript, data acquisition, study concept or design, analysis or interpretation of data, accepts responsibility for conduct of research and final approval, study supervision, obtaining funding. Mary M. Reilly: drafting/revising the manuscript, data acquisition, study concept or design, analysis or interpretation of data, accepts responsibility for conduct of research and final approval, study supervision, obtaining funding.

\section{Study funding}

A.C. is funded by the Inherited Neuropathy Consortium (INC), which is a part of the NIH Rare Diseases Clinical Research Network (RDCRN) (U54NS065712), Medical 
Research Council (MR/179744), and Wellcome Trust (204841/Z/16/Z). H.H. and M.M.R. are supported by the Medical Research Council (MRC), MRC center grant (G0601943), and the National Institutes of Neurologic Diseases and Stroke (NINDS) and Office of Rare Diseases (U54NS065712). H.H. is also supported by Ataxia UK, The MSA Trust, MDUK, and The Muscular Dystrophy Association. The INC (U54NS065712) is a part of the National Center for Advancing Translational Sciences (NCATS) RDCRN. RDCRN is an initiative of the Office of Rare Diseases Research. NCATS is funded through a collaboration between NCATS and NINDS.

\section{Disclosure}

The authors report no disclosures relevant to the manuscript. Go to Neurology.org/N for full disclosures.

\section{Publication history}

Received by Neurology March 14, 2019. Accepted in final form June 24, 2019.

\section{References}

1. Rossor AM, Tomaselli PJ, Reilly MM. Recent advances in the genetic neuropathies. Curr Opin Neurol 2016;29:537-548.

2. Pisciotta C, Shy ME. Neuropathy. Handb Clin Neurol 2018;148:653-665.

3. Fridman V, Bundy B, Reilly MM, et al. CMT subtypes and disease burden in patients enrolled in the Inherited Neuropathies Consortium natural history study: a crosssectional analysis. J Neurol Neurosurg Psychiatry 2015;86:873-878.

4. Murphy SM, Laura M, Fawcett K, et al. Charcot-Marie-Tooth disease: frequency of genetic subtypes and guidelines for genetic testing. J Neurol Neurosurg Psychiatry 2012;83:706-710.

5. Saporta ASD, Sottile SL, Miller LJ, Feely SME, Siskind CE, Shy ME. Charcot-MarieTooth disease subtypes and genetic testing strategies. Ann Neurol 2011;69:22-33.

6. Drew AP, Zhu D, Kidambi A, et al. Improved inherited peripheral neuropathy genetic diagnosis by whole-exome sequencing. Mol Genet Genomic Med 2015;3:143-154.

7. Choi BO, Koo SK, Park MH, et al. Exome sequencing is an efficient tool for genetic screening of Charcot-Marie-Tooth disease. Hum Mutat 2012;33:1610-1615.

8. Schabhüttl M, Wieland $\mathrm{T}$, Senderek J, et al. Whole-exome sequencing in patients with inherited neuropathies: outcome and challenges. J Neurol 2014;261:970-982.

9. Gonzaga-Jauregui C, Harel T, Gambin T, et al. Exome sequence analysis suggests that genetic burden contributes to phenotypic variability and complex neuropathy. Cell Rep 2015;12:1169-1183.

10. Nam SH, Hong YB, Hyun YS, et al. Identification of genetic causes of inherited peripheral neuropathies by targeted gene panel sequencing. Mol Cell 2016;39: 382-388.

11. Wang W, Wang C, Dawson DB, et al. Target-enrichment sequencing and copy number evaluation in inherited polyneuropathy. Neurology 2016;86:1762-1771.

12. Lupo V, García-García F, Sancho P, et al. Assessment of targeted next-generation sequencing as a tool for the diagnosis of Charcot-Marie-Tooth disease and hereditary motor neuropathy. J Mol Diagn 2016;18:225-234.

13. Ylikallio E, Johari M, Konovalova S, et al. Targeted next-generation sequencing reveals further genetic heterogeneity in axonal Charcot-Marie-Tooth neuropathy and a mutation in HSPB1. Eur J Hum Genet 2014;22:522-527.
14. Laššuthová $\mathrm{P}$, Šafka Brožková D, Krůtová M, et al. Improving diagnosis of inherited peripheral neuropathies through gene panel analysis. Orphanet J Rare Dis 2016;11: 118.

15. Høyer H, Braathen GJ, Busk ØL, et al. Genetic diagnosis of Charcot-Marie-Tooth disease in a population by next-generation sequencing. Biomed Res Int 2014;2014: 210401.

16. Høyer H, Braathen GJ, Busk ØL, et al. Corrigendum to "genetic diagnosis of CharcotMarie-Tooth disease in a population by next-generation sequencing". Biomed Res Int 2015;2015:314651.

17. Antoniadi T, Buxton C, Dennis G, et al. Application of targeted multi-gene panel testing for the diagnosis of inherited peripheral neuropathy provides a high diagnostic yield with unexpected phenotype-genotype variability. BMC Med Genet 2015;16:84.

18. Vaeth S, Christensen R, Dunø M, et al. Genetic analysis of Charcot-Marie-Tooth disease in Denmark and the implementation of a next generation sequencing platform. Eur J Med Genet 2019;68:1-8.

19. Dohrn MF, Glöckle N, Mulahasanovic L, et al. Frequent genes in rare diseases: panelbased next generation sequencing to disclose causal mutations in hereditary neuropathies. J Neurochem 2017;143:507-522.

20. Yoshimura A, Yuan JH, Hashiguchi A, et al. Genetic profile and onset features of 1005 patients with Charcot-Marie-Tooth disease in Japan. J Neurol Neurosurg Psychiatry 2019;90:195-202.

21. Richards S, Aziz N, Bale S, et al. Standards and guidelines for the interpretation of sequence variants: a joint consensus recommendation of the American College of Medical Genetics and Genomics and the Association for Molecular Pathology. Genet Med 2015; 17:405-424

22. Murphy SM, Herrmann DN, McDermott MP, et al. Reliability of the CMT neuropathy score (second version) in Charcot-Marie-Tooth disease. J Peripher Nerv Syst 2011;16:191-198.

23. Cortese A, Manole A, Ashokkumar B, et al. Functional validation of non-coding variants of GJB1 in patients with CMTX1. Neuromuscul Disord 2017;27:S25.

24. Panosyan FB, Laura M, Rossor AM, et al. Cross-sectional analysis of a large cohort with X-linked Charcot-Marie-Tooth disease (CMTX1). Neurology 2017;89: 927-935.

25. Tomaselli PJ, Rossor AM, Horga A, et al. Mutations in noncoding regions of GJB1 are a major cause of X-linked CMT. Neurology 2017;88:1445-1453.

26. Tomaselli PJ, Rossor AM, Polke JM, Poh R, Blake J, Reilly MM. Semi-dominant mutations in MFN2-related neuropathy and implications for genetic counselling. J Peripher Nerv Syst 2016;21:52-54.

27. Tomaselli PJ, Horga A, Rossor AM, et al. IGHMBP2 mutation associated with organspecific autonomic dysfunction. Neuromuscul Disord 2018;28:1012-1015.

28. Cortese A, Simone R, Sullivan R, et al. Biallelic expansion of an intronic repeat in RFC1 is a common cause of late-onset ataxia. Nat Genet 2019;51:649-658.

29. Ishiura H, Doi K, Mitsui J, et al. Expansions of intronic TTTCA and TTTTA repeats in benign adult familial myoclonic epilepsy. Nat Genet 2018;50:581-590.

30. DeJesus-Hernandez M, Mackenzie IR, Boeve BF, et al. Expanded GGGGCC hexanucleotide repeat in noncoding region of C9ORF72 causes chromosome 9p-linked FTD and ALS. Neuron 2011;72:245-256.

31. Renton AE, Majounie E, Waite A, et al. A hexanucleotide repeat expansion in C9ORF72 is the cause of chromosome 9p21-linked ALS-FTD. Neuron 2011;72: 257-268.

32. Cutrupi AN, Brewer MH, Nicholson GA, Kennerson ML. Structural variations causing inherited peripheral neuropathies: a paradigm for understanding genomic organization, chromatin interactions, and gene dysregulation. Mol Genet Genomic Med 2018;6:422-433.

33. Salpietro V, Manole A, Efthymiou S, Houlden H. A review of copy number variants in inherited neuropathies. Curr Genomics 2018;19:412-419.

34. Laššuthová P, Mazanec R, Vondráček P, et al. High frequency of SH3TC2 mutations in Czech HMSN I patients. Clin Genet 2011;80:334-345.

35. Piscosquito G, Saveri P, Magri S, et al. Screening for SH3TC2 gene mutations in a series of demyelinating recessive Charcot-Marie-Tooth disease (CMT4). J Peripher Nerv Syst 2016;21:142-149.

36. Houlden H, Laura M, Ginsberg L, et al. The phenotype of Charcot-Marie-Tooth disease type 4C due to SH3TC2 mutations and possible predisposition to an inflammatory neuropathy. Neuromuscul Disord2009;19:264-269. 


\section{Neurology}

\section{Targeted next-generation sequencing panels in the diagnosis of Charcot-Marie-Tooth disease}

Andrea Cortese, Janel E. Wilcox, James M. Polke, et al.

Neurology 2020;94;e51-e61 Published Online before print December 11, 2019

DOI 10.1212/WNL.0000000000008672

\section{This information is current as of December 11, 2019}

\section{Updated Information \& Services}

References

Citations

Subspecialty Collections

Errata

Permissions \& Licensing

Reprints including high resolution figures, can be found at: http://n.neurology.org/content/94/1/e51.full

This article cites 36 articles, 6 of which you can access for free at: http://n.neurology.org/content/94/1/e51.full\#ref-list-1

This article has been cited by 1 HighWire-hosted articles: http://n.neurology.org/content/94/1/e51.full\#\#otherarticles

This article, along with others on similar topics, appears in the following collection(s):

All Genetics

http://n.neurology.org/cgi/collection/all_genetics

All Neuromuscular Disease

http://n.neurology.org/cgi/collection/all_neuromuscular_disease

Peripheral neuropathy

http://n.neurology.org/cgi/collection/peripheral_neuropathy

An erratum has been published regarding this article. Please see next page or:

/content/98/9/384.2.full.pdf

/content/99/1/42.full.pdf

Information about reproducing this article in parts (figures,tables) or in its entirety can be found online at:

http://www.neurology.org/about/about_the_journal\#permissions

Information about ordering reprints can be found online:

http://n.neurology.org/subscribers/advertise

Neurology ${ }^{\circledR}$ is the official journal of the American Academy of Neurology. Published continuously since 1951, it is now a weekly with 48 issues per year. Copyright Copyright ( 2019 The Author(s). Published by Wolters Kluwer Health, Inc. on behalf of the American Academy of Neurology.. All rights reserved. Print ISSN: 0028-3878. Online ISSN: 1526-632X.

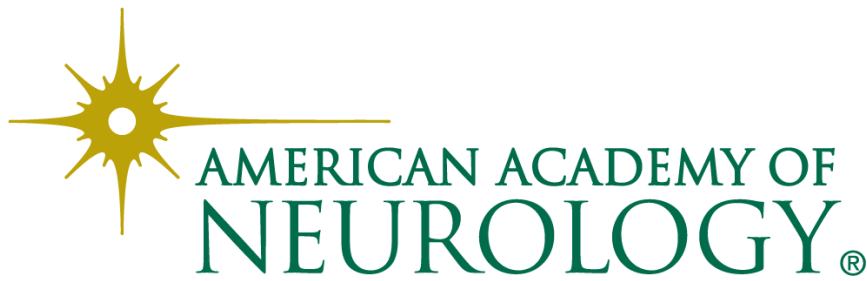




\section{Stereotyped Upper Limb Movement in MECP2 Duplication Syndrome}

Neurology ${ }^{\circledR}$ 2022;98:384. doi:10.1212/WNL.0000000000012757

In the Video NeuroImage article "Stereotyped Upper Limb Movement in MECP2 Duplication Syndrome" by Wakabayashi et al., the first sentence should read: "A 23-year-old man had epilepsy, intellectual disability, and a stereotyped movement (Figure 1 and Video 1), which was exacerbated by emotion." The authors regret the error.

\section{Reference}

1. Wakabayashi T, Fukumura S, Takahashi S, et al. Stereotyped upper limb movement in MECP2 duplication syndrome. Neurology. 2021, 97(2):92-94.

\section{Targeted Next-Generation Sequencing Panels in the Diagnosis of Charcot-Marie-Tooth Disease}

Neurology ${ }^{\circledR}$ 2022;98:384. doi:10.1212/WNL.0000000000010635

In the article "Targeted Next-Generation Sequencing Panels in the Diagnosis of CharcotMarie-Tooth Disease" by Cortese et al., ${ }^{1}$ the gene named throughout the article should be FGD4. In the amended supplementary table e-2 (doi.org/10.5061/dryad.kp8pb51), the mutation in patient 111 should be PMP22: c.68G $>\mathrm{C}$ p. (Thr23Arg), and the mutation in patient 21 should be GARS: c.880G>C p.Gly294Arg. The authors regret the errors.

\section{Reference}

1. Cortese A, Wilcox JE, Polke JM, et al. Targeted next-generation sequencing panels in the diagnosis of Charcot-Marie-Tooth disease. Neurology. 2020;94(1):e51-e61.

\section{CORRECTION \& REPLACEMENT}

\section{What Is the Role of Stathmin-2 in Axonal Biology and Degeneration?}

Neurology ${ }^{\circledR}$ 2022;98:384. doi:10.1212/WNL.0000000000013018

In the Basic Science in the Clinic article "What Is the Role of Stathmin-2 in Axonal Biology and Degeneration?" by Benarroch, ${ }^{1}$ a reference to a study by Melamed et al. ${ }^{2}$ was inadvertently omitted at the beginning of the article and miscited elsewhere. The updated references and citations have been added in the replacement version of the article.

In addition, statements regarding TDP-43 in the first paragraph under the "Relationship Among STMN2, TDP-43, and Axonal Degeneration" heading have been corrected in the replacement version of the article. The author agrees with a reader who pointed out that the original wording was not substantiated.

The author regrets the omissions and errors. The original version with the changes highlighted is available from a link in the corrected article.

\section{References}

1. Benarroch E. What is the role of stathmin-2 in axonal biology and degeneration? Neurology. 2021;97(7):330-333.

2. Melamed Z, Lopez-Erauskin J, Baughn MW, et al. Premature polyadenylation-mediated loss of stathmin-2 is a hallmark of TDP-43dependent neurodegeneration. Nat Neurosci. 2019;22(2):180-190. 


\section{Disputes \& Debates: Editors' Choice}

Steven Galetta, MD, FAAN, Editor

Aravind Ganesh, MD, DPhil, FRCPC, Deputy Editor

Ariane Lewis, MD, Deputy Editor

James E. Siegler III, MD, Deputy Editor

\section{Editors' Note: Shoulder-Tap Test for Functional Gait Disorders: A Sign of Abnormal Anticipatory Behavior}

Dr. Coebergh and colleagues described exaggerated postural responses in 25 patients with functional gait disorders, following a sudden shoulder tap applied by an examiner from behind the patient. In response, Dr. Geroin et al. comment that in their own population of patients with functional neurologic disorders, a light touch on the shoulders seemed to provide fewer false-positive results, given that a sudden tap could evoke exaggerated responses in patients with disorders such as hyperekplexia or stiff-person syndrome. They also note that it is not necessary to see an intact response to a retropulsion test in patients with functional gait disorders to flag their shoulder-test response as incongruent. Responding to these comments, Dr. Coebergh agrees that a light touch would likely suffice, noting that the actual contact with the shoulders in the described shoulder-tap test is light, while also highlighting work being performed by their group in identifying sensory thresholds of force at which incongruent postural responses occur in such patients. To illustrate the potential value of observing incongruity in responses to shoulder-tap vs retropulsive stimuli in patients with functional gait disorder, Dr. Coebergh highlights a case of a patient with stiff-person syndrome misdiagnosed as a functional neurologic disorder, in whom such incongruity was not observed. This exchange demonstrates the enduring value of systematic clinical examinations and observations in improving the diagnosis of functional neurologic disorders.

\section{Reader Response: Shoulder-Tap Test for Functional Gait Disorders: A Sign of Abnormal Anticipatory Behavior}

\footnotetext{
Christian Geroin (Verona, Italy), Jorik Nonnekes (Nijmegen, the Netherlands), Serena Camozzi (Verona, Italy), Bastiaan R. Bloem (Nijmegen, the Netherlands), and Michele Tinazzi (Verona, Italy) Neurology ${ }^{\circledR}$ 2022;99:38-39. doi:10.1212/WNL.0000000000200866
}

In a recent report, Coebergh et al. ${ }^{1}$ introduced the shoulder-tap test, which helps to reveal incongruity in patients with functional gait disorders. Specifically, the authors observed an exaggerated postural response in $82 \%$ of patients, following a gentle shoulder tap applied from behind the patient. ${ }^{1}$ We applaud the described approach because incongruencies of symptoms and signs have great diagnostic value when diagnosing a functional neurologic disorder. ${ }^{2-4} \mathrm{We}$ hope to extend the findings of Coebergh et al. by making 2 additional points.

As observed in our population of functional neurologic disorders, a light touch on the shoulders instead of a shoulder tap might be more informative and provide fewer false-positive results because a sudden tap can evoke an exaggerated postural response in patients with hyperekplexia or stiff-person syndrome. This movement would then incorrectly be classified as an incongruent response. In addition, the authors state that incongruity involves an abnormal response to the shoulder tap combined with an intact response to the normal retropulsion test. We would argue 
that an isolated abnormal response to a mere touch to the shoulders would already suggest incongruity, with a consideration for rare organic disorders such as hyperekplexia and stiff-person syndrome.

1. Coebergh J, Zimianiti I, Kaski D. Shoulder-tap test for functional gait disorders: a sign of abnormal anticipatory behavior. Neurology. 2021;97(23):1070-1071.

2. Espay AJ, Aybek S, Carson A, et al. Current concepts in diagnosis and treatment of functional neurological disorders. JAMA Neurol. 2018;75(9):1132-1141.

3. Nonnekes J, Růžička E, Serranová T, Reich SG, Bloem BR, Hallett M. Functional gait disorders: a sign-based approach. Neurology. 2020; 94(24):1093-1099.

4. Gupta A, Lang AE. Psychogenic movement disorders. Curr Opin Neurol. 2009;22(4):430-436.

Copyright (c) 2022 American Academy of Neurology

\section{Author Response: Shoulder-Tap Test for Functional Gait Disorders: A Sign of Abnormal Anticipatory Behavior}

Jan A. Coebergh (Chertsey, UK)

Neurology ${ }^{\circledR}$ 2022;99:39. doi:10.1212/WNL.0000000000200867

We welcome the comments by Dr. Geroin et al. ${ }^{1}$ on our article. We agree that a light touch may be a sufficient stimulus to induce an anticipatory postural response in patients with functional gait disorders, without the need for a "tap." Although the video linked to our article shows a rapid downward movement of the examiner's hands onto the shoulders, the actual contact with the shoulders is in fact light, lending credence to our esteemed colleagues' observations. Whether there exists a sensory threshold of force, at which an incongruent or inappropriate postural response occurs following a touch to the shoulders, is an interesting question that we hope to be able to address in our future work. In fact, we are extending our work to explore the shoulder-tap test in elderly people with a fear of falling-a common symptom in which abnormal anticipatory behaviors likely exist and identification of such thresholds may be of particular interest.

We also agree that an abnormal response to a light shoulder tap would be an incongruent response to such a stimulus, but, as we describe in our article, a normal response to a retropulsive stimulus or a pull after an abnormal shoulder tap provides further evidence of incongruity.

Finally, we have recently seen a patient with stiff-person syndrome who had been previously misdiagnosed as having a functional neurologic disorder; the clue to the actual diagnosis, beyond the presence of auditory startle and hyperlordosis, was indeed the absence of any incongruity in postural responses. We therefore appreciate the comments regarding this rare but treatable disorder and the importance of avoiding undue force during a shoulder tap or touch that would render interpretation of the ensuing behavior more challenging.

1. Coebergh J, Zimianiti I, Kaski D. Shoulder-tap test for functional gait disorders: a sign of abnormal anticipatory behavior. Neurology. 2021;97(23):1070-1071

Copyright @ 2022 American Academy of Neurology 
CORRECTION

\section{In Vivo Diagnosis of Synucleinopathies}

A Comparative Study of Skin Biopsy and RT-QuIC

Neurology ${ }^{\circledR}$ 2022;99:40-42. doi:10.1212/WNL.0000000000200689

In the article "In Vivo Diagnosis of Synucleinopathies: A Comparative Study of Skin Biopsy and RT-

QuIC" by Donadio et al., the first paragraph of the Methods section should indicate that of the 31

Table 4 Immunofluorescence and Real-Time Quaking-Induced Conversion (RT-QulC) Results of Skin and CSF Samples

\begin{tabular}{|c|c|c|c|c|c|c|}
\hline \multirow[b]{2}{*}{ Variable } & \multirow[b]{2}{*}{ Cases, $\mathbf{n}$} & \multirow[b]{2}{*}{ Diagnosis } & \multicolumn{3}{|l|}{ Skin } & \multirow[b]{2}{*}{ CSF, RT-QuIC } \\
\hline & & & Protocol & Immunofluorescence & RT-QuIC & \\
\hline \multirow[t]{19}{*}{ Synucleinopathies } & 1 & PD (1 patient $\left.{ }^{\mathrm{a}}\right)$ & III & + & + & + \\
\hline & 2 & PD (6 patients $)$ & III & + & + & ND \\
\hline & 3 & PD (1 patient) & ॥ & + & + & + \\
\hline & 4 & PD (3 patients $)$ & ॥ & + & + & ND \\
\hline & 5 & PD (5 patients) & III & + & + & ND \\
\hline & 6 & PD (1 patient $\left.{ }^{\mathrm{a}}\right)$ & 1 & - & + & ND \\
\hline & 7 & MSA-C (1 patient) & III & + & + & + \\
\hline & 8 & MSA-P (3 patients) & 1 & + & + & ND \\
\hline & 9 & MSA-P (1 patient) & 1 & - & - & ND \\
\hline & 10 & MSA-P (1 patient) & 1 & + & - & ND \\
\hline & 11 & MSA-P (1 patient) & 1 & - & + & ND \\
\hline & 12 & MSA-C (1 patient) & 1 & + & ND & - \\
\hline & 13 & Lewy body dementia (1 patient) & III & + & - & ND \\
\hline & 14 & Lewy body dementia (2 patients) & II & + & + & + \\
\hline & 15 & Lewy body dementia (1 patient) & 1 & + & + & + \\
\hline & 16 & Lewy body dementia (1 patient) & 1 & + & + & ND \\
\hline & 17 & PAF (1 patient) & II & + & + & + \\
\hline & 18 & PAF (1 patient) & $\|$ & - & - & - \\
\hline & 19 & PAF (1 patient) & 1 & + & + & ND \\
\hline \multirow[t]{10}{*}{ Nonsynucleinopathies } & 1 & AD (5 patients) & III & - & - & - \\
\hline & 2 & AD (2 patients) & III & - & + & - \\
\hline & 3 & AD (1 patient) & III & - & - & ND \\
\hline & 4 & AD (1 patient) & III & -- & + & ND \\
\hline & 5 & AD (2 patients) & II & - & - & - \\
\hline & 6 & AD (1 patient) & II & - & - & ND \\
\hline & 7 & AD (2 patients) & 1 & - & - & - \\
\hline & 8 & AD (1 patient) & 1 & - & - & ND \\
\hline & 9 & PSP (1 patient) & III & - & + & ND \\
\hline & 10 & PSP (2 patients) & II & - & - & - \\
\hline
\end{tabular}


Table 4 Immunofluorescence and Real-Time Quaking-Induced Conversion (RT-QuIC) Results of Skin and CSF Samples (continued)

\begin{tabular}{|c|c|c|c|c|c|c|}
\hline \multirow[b]{2}{*}{ Variable } & \multirow[b]{2}{*}{ Cases, $\mathbf{n}$} & \multirow[b]{2}{*}{ Diagnosis } & \multicolumn{3}{|l|}{ Skin } & \multirow[b]{2}{*}{ CSF, RT-QuIC } \\
\hline & & & Protocol & Immunofluorescence & RT-QuIC & \\
\hline & 11 & CBS ( 1 patient) & II & - & - & ND \\
\hline & 12 & CBS (1 patient) & ॥ & - & + & ND \\
\hline & 13 & Vascular parkinsonism (3 patients ${ }^{a}$ ) & III & - & - & ND \\
\hline & 13 & Vascular parkinsonism (1 patient) & II & - & - & - \\
\hline & 14 & Vascular parkinsonism (2 patients ${ }^{a}$ ) & II & - & - & ND \\
\hline & 15 & Vascular parkinsonism (2 patients) & I & - & - & - \\
\hline & 16 & latrogenic parkinsonism (1 patient) & I & - & - & ND \\
\hline & 17 & Autoimmune parkinsonism (1 patient) & II & - & - & - \\
\hline & 18 & Vascular dementia (1 patient) & III & - & - & - \\
\hline & 19 & Vascular dementia (1 patient) & II & - & + & - \\
\hline & 20 & ALS (1 patient) & III & - & + & - \\
\hline & 21 & ALS (1 patient) & II & - & + & - \\
\hline & 22 & ALS (3 patients) & I & - & - & - \\
\hline & 23 & ALS (1 patient) & I & - & + & ND \\
\hline \multirow[t]{19}{*}{ Controls } & 1 & Small fiber neuropathy (3 patients) & III & - & - & - \\
\hline & 2 & Small fiber neuropathy (2 patients) & III & - & - & ND \\
\hline & 3 & Small fiber neuropathy (1 patient) & I & - & - & - \\
\hline & 4 & Small fiber neuropathy (1 patient) & I & - & - & ND \\
\hline & 5 & Peripheral neuropathy (1 patient) & III & - & + & ND \\
\hline & 6 & Peripheral neuropathy (1 patient) & II & - & - & - \\
\hline & 7 & Peripheral neuropathy (1 patient) & II & - & + & - \\
\hline & 8 & Peripheral neuropathy (1 patient) & I & - & - & - \\
\hline & 9 & Peripheral neuropathy (1 patient) & I & - & - & ND \\
\hline & 10 & CIDP (1 patient) & I & - & - & - \\
\hline & 11 & Wernicke encephalopathy (1 patient) & I & - & - & - \\
\hline & 12 & Depression (1 patient) & III & - & - & - \\
\hline & 13 & Depression (2 patients) & III & - & - & ND \\
\hline & 14 & Depression (2 patients) & II & - & - & - \\
\hline & 15 & Cerebral vasculitis (1 patient) & II & - & - & - \\
\hline & 16 & Cerebral vasculitis ( 1 patient) & II & - & ND & - \\
\hline & 17 & SCD (1 patient) & III & - & + & - \\
\hline & 18 & SCD (1 patient) & II & - & - & - \\
\hline & 19 & Stiff-person syndrome (1 patient) & I & - & - & ND \\
\hline
\end{tabular}

Abbreviations: $A D=$ Alzheimer disease; $A L S=$ amyotrophic lateral sclerosis; $C B S=$ corticobasal syndrome; CIDP = chronic inflammatory demyelinating polyneuropathy; MSA-C = multiple system atrophy, cerebellar type; MSA-P = multiple system atrophy, parkinsonian type; ND = not done; PAF = pure autonomic failure; PD = Parkinson disease; PSP = progressive supranuclear palsy; SCD = subjective cognitive disorder.

a Patients from whom 10 skin samples were taken; in the remaining patients, 8 skin samples were taken combining the routine and study protocols (see Methods for more details). 
patients with synucleinopathies, 15 were patients with Parkinson disease, and of the 38 patients with nonsynucleinopathies, 7 were patients with vascular parkinsonism. The authors regret the errors.

In addition, the Diagnosis column of Table 4 should read "patients" in parentheses, not "points." See the corrected Table 4. The publisher regrets the errors.

\section{Reference}

1 Donadio V, Wang Z, Incensi A, et al. In vivo diagnosis of synucleinopathies: a comparative study of skin biopsy and RT-QuIC. Neurology. 2021;96(20): e2513-e2524.

\section{NOTICE}

\section{Dual Publication: Spinal Cord Injury, Vertebral Artery Dissection, and Cerebellar Strokes After Chiropractic Manipulation}

Neurology ${ }^{\circledR}$ 2022;99:42. doi:10.1212/WNL.0000000000200334

The Editors of Neurology ${ }^{\circledR}$ and Internal and Emergency Medicine issue a notice of publication of 2 reports of a single patient written by 2 different author groups.

Macêdo MB, Shinjo SK, Domiciano DS. Breaking the Diagnosis: Ankylosing Spondylitis Evidenced by Cervical Fracture following Spine Manipulation. Intern Emerg Med 2021. DOI: $10.1007 / \mathrm{s} 11739-021-02829-2$.

Ramos GB, Martins RR, Souza JCC, Falcão FCSEB, Lopes CCB, Andrade ALG, Silva GD. Spinal Cord Injury, Vertebral Artery Dissection, and Cerebellar Strokes after Chiropractic Manipulation. Neurology 2021. DOI: 10.1212/WNL.0000000000013078.

The first article was published in Internal and Emergency Medicine. The journal received it on July 20, 2021, accepted it on August 10, 2021, and published it online on August 20, 2021. The second article was published in Neurology. It was received on July 16, 2021, accepted on November 4, 2021, and published online on November 18, 2021. The 2 case reports were based on the same patient and shared a common image.

Both case reports were written by authors from the Faculdade de Medicina, Universidade de São Paulo. The authors of the article published in Internal and Emergency Medicine were affiliated with the Department of Rheumatology, and the authors of the Neurology article were affiliated with the Department of Neurology.

The authors of both articles were contacted and asked for an explanation for the dual publication. Both teams of authors explained that they cared for the patient during the hospital admission and that they were unaware of the submission by the other team. The focus of the articles is different: one focused on bone injury and emergency care and the other on the neurologic aspects of the case. Both author groups apologize for the duplicate submissions.

A reader first notified Neurology that the case had been published in the 2 journals and a brief report was submitted to Neurology's Disputes \& Debates section on November 29, 2021. ${ }^{1}$

\section{Reference}

1. Trager RJ, Garcia JA. Disputes \& Debates: Rapid Online Correspondence. Reader Response: Spinal Cord Injury, Vertebral Artery Dissection, and Cerebellar Strokes after Chiropractic Manipulation. n.neurology.org/content/reader-response-spinal-cord-injury-vertebral-arterydissection-and-cerebellar-strokes-after.

Copyright (c) 2022 American Academy of Neurology 